\title{
NOVAS PERSPECTIVAS SOBRE O DEBATE DA DICOTOMIA SOCIEDADE $\times$ NATUREZA A PARTIR DA ECOLOGIA HISTÓRICA: INTRODUÇÃO E DOMESTICAÇÃO DE UMA ESPÉCIE EXÓTICA NA MATAATLÂNTICA
}

CURRENT PERSPECTIVE ON THE SOCIETY × NATURE DICOTOMY DEBATE FROM HISTORICAL ECOLOGY: INTRODUCTION AND DOMESTICATION OF AN EXOTIC SPECIES IN THE ATLANTIC FOREST

\section{Alexandro Solórzano}

Professor adjunto no Departamento de Geografia e Meio Ambiente da Pontifícia Universidade Católica do Rio de Janeiro (PUC-Rio). E-mail: alexandrosol@gmail.com. 


\section{RESUMO}

A visão de uma natureza intocada ainda é dominante no ambientalismo moderno e adotada por muitos cientistas que buscam linhas de base como modelos a serem alcançados por metas de conservação da biodiversidade. Nas últimas décadas as contribuições da história ambiental e da ecologia histórica trouxeram reflexões relevantes sobre a história de mútua transformação da cultura e da natureza, em uma clara tentativa de romper com a clássica visão dicotômica. Nossa proposta é apresentar novos caminhos para a interpretação das paisagens contemporâneas em que o homem e as demais espécies apresentam uma rica história de interação. Foi demonstrado o quão entrelaçadas estão as florestas com a urbe carioca, sendo compreendidas como sistemas socioecológicos (SSE). Também foi aprofundada a discussão sobre a dicotomia espécie nativa $\times$ exótica. A jaqueira é um componente importante do sistema socioecológico florestacidade do Rio de Janeiro, atualmente indicando na paisagem florestal os espaços marcados pela história e pela cultura da sociedade carioca.

PALAVRAS-CHAVE: sistemas socioecológicos; jaqueira; história ambiental; transformação da paisagem.

\section{ABSTRACT}

Pristine nature, or wilderness, is still a dominant view in modern environmentalism and adopted by many scientists who seek baselines as models to be achieved by biodiversity conservation goals. In the last decades the contributions of Environmental History and Historical Ecology have brought relevant reflections on the history of mutual transformation of culture and nature, in a clear attempt to overcome the classic dichotomous perspective. Our proposal is to present new ways of interpreting contemporary landscapes in which humans and other species have a rich history of interaction. We demonstrated how intertwined the forests are with the city of Rio de Janeiro, being understood as socioecological systems (SSE). We also discussed the native x exotic species dichotomy. The jackfruit is an important component of the forest-city socioecological system, currently indicating in the forest landscape the spaces marked by the history and culture of Rio de Janeiro.

KEYWORDS: socio-ecological systems; jackfruit; environmental history; landscape trasnformation. 


\section{Introdução}

Na acepção mais comum, quando falamos de natureza, nos referimos ao conjunto de espécies que ocorrem em determinado ambiente e que não inclui o ser humano. Em poucas palavras, natureza é onde o ser humano não está. Essa visão clássica ocidental faz parte daquilo que é conhecido como a dicotomia sociedade $\times$ natureza, ou homem $\times$ natureza ou ainda cultura $\times$ natureza. William Cronon, em seu célebre texto "The trouble with wilderness: or, getting back to the wrong nature" (1996), faz uma narrativa de como foi construída a ideia de natureza selvagem e intocada pelo homem, e propõe uma nova forma de pensar wilderness. Essa construção cultural que é o conceito de wilderness se tornou o alicerce do movimento ambientalista moderno, especialmente nos Estados Unidos.

[...] a natureza selvagem permanece como o último lugar remanescente onde a civilização, aquela doença humana, não infectou completamente a terra [...] a natureza intocada se apresenta como o melhor antídoto para a nossa espécie humana, um refúgio que devemos recuperar se esperamos salvar o planeta. (CRONON, 1996, p. 7, tradução nossa). ${ }^{1}$

Podemos traçar um paralelo direto entre o conceito de wilderness com o de natureza, que representa uma visão específica da cultura europeia cerca de 300 anos atrás. Wilderness representava os espaços não civilizados, de vida selvagem e, portanto, perigosos e até ruins para o homem civilizado. Já no século XIX esse temor da natureza selvagem se transformou em reverência e inspiração para pensadores como Henry David Thureau e John Muir, pais do ambientalismo moderno, influenciados pelo romantismo europeu do século XVIII (CRONON, I996). Nasce assim a ideia de uma natureza divina e selvagem, a qual o ser humano deveria visitar para se inspirar, contemplar e fundamentalmente se proteger das garras gananciosas da sociedade urbano-industrial em plena expansão. Essa visão ainda é bastante moderna para muitos cientistas, especialmente biólogos e ecólogos que buscam linhas de base, ou ecossistemas históricos de referência, como modelos a serem alcançados por metas de restauração ecológica e conservação da biodiversidade. Essa linha de base é, portanto, o estado ecológico de referência, um momento antes da intervenção maléfica do homem, especificamente da chegada do europeu, ou até mesmo antes da existência do ser humano (MARRIS, 2OII). Voltar ao estado original ou pristino, portanto, seria a única forma de curar o planeta da doença da humanidade, sendo o ideal, o bom ou o estado correto da natureza (MARRIS, 2OII).

Ambientalistas modernos e as ciências naturais, de modo geral, tendem a colocar o ser humano como externos às dinâmicas dos ecossistemas, reduzindo sua interação ecológica pela sua capacidade destruidora, por um lado, ou pela sua capacidade de dominação, domesticação e

\footnotetext{
1 “[...] wilderness stands as the last remaining place where civilization, that all too human disease, has not fully infected the earth [...] wilderness presents itself as the best antidote to our human selves, a refuge we must somehow recover if we hope to save the planet" (CRONON, 1996, p. 7).
} 
engenharia das estruturas e processos ecossistêmicos, de outro (CABRAL et al., 20I6). Quando A. G. Tansley propôs o conceito de ecossistema como um sistema complexo composto por organismos e seu ambiente físico ele também questionou a tendência geral de arbitrariamente separar o ser humano da natureza e, assim, colocando-o como parte do ecossistema:

[...] seria difícil, para não dizer impossível, traçar uma linha natural entre as atividades das sociedades humanas, que presumivelmente se encaixavam e formavam partes de "comunidades bióticas" e as atividades humanas destrutivas do mundo moderno. O homem é parte da "natureza" ou não? [...] Considerado como um fator biótico excepcionalmente poderoso, que perturba cada vez mais o equilíbrio dos ecossistemas preexistentes e acaba destruindo-os, ao mesmo tempo formando novos ecossistemas de natureza muito diferente, a atividade humana encontra seu lugar adequado na ecologia. (TANSLEY, 1935, p. 303, tradução nossa). ${ }^{2}$

Mas essa tentativa foi mais uma exceção do que uma regra, e a narrativa ecológica que dominou as discussões ambientais na segunda metade do século XX era apoiada no mito de uma natureza intocada. Uma das concretizações mais claras desse pensamento foi o desenvolvimento de um modelo de conservação da natureza livre da presença do ser humano, para satisfazer as necessidades do homem urbano-industrial, e que foi exportada para todo o mundo. Esse modelo, conhecido como modelo de Yellowstone, gerou consequências desastrosas para as populações vivendo em direto contato com os diferentes ecossistemas (DIEGUES, I996).

A narrativa declensionista, ou seja, de declínio e degradação da natureza pelas mãos humanas, além de cansativa para muitos historiadores ambientais e depressiva para a atual juventude, deixa de lado grande parte da construção histórica do mundo habitado pelo homem, bem como exclui narrativas de outras formas de interação (MCNEIL, 20IO). Essa narrativa de degradação nos diz muito sobre como, em grande parte, os humanos modificaram o planeta, mas não nos informa como, nesse processo, o ser humano se transformou, não apenas biologicamente, mas culturalmente (CABRAL et al., 2016).

Nas últimas décadas as contribuições da história ambiental e da ecologia histórica trouxeram reflexões relevantes sobre a história de mútua transformação da cultura e da natureza, em uma clara tentativa de romper com a clássica visão dicotômica:

[...] a separação do homem da natureza é uma arbitrariedade cultural, sem uma base científica para poder determinar em qual momento histórico que houve essa ruptura. Alguns datam isso ao neolítico, quando o homem domesticou algumas espécies, permitindo se fixar em um território, dando início à primeira revolução

\footnotetext{
2 "[...] it would be difficult, not to say impossible, to draw a natural line between the activities of the human tribes which presumably fitted into and formed parts of " biotic communities "and the destructive human activities of the modern world. Is man part of "nature" or not? [...] Regarded as an exceptionally powerful biotic factor which increasingly upsets the equilibrium of preexisting ecosystems and eventually destroys them, at the same time forming new ones of very different nature, human activity finds its proper place in ecology" (TANSLEY, 1935, p. 303).
} 
da agricultura. Assim, a investigação da história das relações ecológicas de sociedades pretéritas, até os dias atuais, é uma importante frente para melhor compreender questões ambientais contemporâneas. (SOLÓRZANO et al., 20I8, p. 20).

$\mathrm{Na}$ área de Antropologia Ecológica, a subdisciplina de Ecologia Histórica pode ser definida, de modo geral, como o estudo das interações homem $\times$ ambiente ao longo do tempo e as resultantes socioecológicas dessa interação, impressas na paisagem (DODARO; REUTER, 2OI7). Assim, a paisagem pode ser entendida como uma unidade física multidimensional que tem características espaciais e temporais e que foi submetida a alguma atividade humana. Nesse sentido, as intencionalidades e as ações humanas podem ser inferidas, ou até lidas como cultura material, a partir da análise da paisagem(BALÉE; ERICKSON, 2006). A ecologia histórica também pode ser definida como a história da paisagem, ou seja, o estudo de ecossistemas passados através da análise (mapeamento e descrição) das mudanças na paisagem ao longo do tempo (CRUMLEY, 1994). Assim,

Ecologia Histórica estuda as atuais relações dialéticas entre atos humanos e atos da natureza, manifestados na paisagem. Práticas são mantidas ou modificadas, decisões são tomadas e ideias ganham forma; a paisagem retém a evidência física dessas atividades mentais. (CRUMLEY, I994, p. I4, tradução nossa). ${ }^{3}$

A paisagem, portanto, retém na forma, na estrutura e na composição de espécies as marcas das culturas que estabeleceram suas interações e seus modos de vida. Espécies animais e vegetais são domesticadas, plantadas, relocadas, introduzidas, caçadas, extraídas, consumidas; por fim, são manejadas e manipuladas pelas populações humanas que delas extraem sua subsistência.

Diante desse debate sobre a dicotomia homem $\times$ natureza, defendemos uma nova maneira de ver a natureza. Entendemos que sim, a natureza está presente em parques nacionais e reservas biológicas, nos mais diversos biomas do mundo. A natureza está presente tanto nos pontos mais remotos da Amazônia, com poucos vestígios humanos, porém com algum; bem como nas florestas urbanas do Rio de Janeiro, repletas de espécies exóticas. Argumentamos aqui que não existe uma natureza intocada. Essa ideia foi construída no ocidente e reforçada pelo ambientalismo moderno, servindo de base ou pressuposto para as ciências da natureza. A ecologia histórica tem revelado o quanto os ecossistemas foram coconstruídos pelo ser humano no passado (BALÉE; ERICKSON, 2006). Ao mesmo tempo, diante das mudanças ambientais globais contemporâneas, alcançando os componentes da atmosfera, da biosfera e da litosfera, vivemos em um período da história do planeta denominado Antropoceno (CRUTZEN, 2002).

Partindo dessa premissa, torna-se cada vez mais difícil compreender tanto a natureza livre de processos sociais quanto entender a sociedade separada dos processos ecológicos, nas mais

\footnotetext{
3 "Historical Ecology traces the ongoing dialectical relations between human acts and acts of nature, made manifest in the landscape. Practices are maintained or modified, decisions are made and ideas are given shape, a landscape retains the physical evidence of these mental activities" (CRUMLEY, 1994, p. 14)
} 
diversas escalas. A paisagem adaptativa em que as espécies interagem tem sido modificada na sua estrutura e na sua composição mais básica, alterando as trajetórias evolutivas das comunidades e afetando os processos ecossistêmicos nos seus componentes bióticos e abióticos (WESTLEY et al., 2002). Portanto, nossa proposta é apresentar novos caminhos para a interpretação das paisagens contemporâneas em que o ser humano e as demais espécies apresentam uma rica história de interação. Para tal, organizei este artigo em três sessões. Na primeira, apresentamos um breve reconto da história ambiental da Mata Atlântica. Esse bioma foi largamente modificado antes da chegada dos portugueses no litoral brasileiro, deixando um claro legado de transformações impressas na paisagem. A segunda sessão apresenta uma compreensão mais aprofundada das florestas urbanas que compõem a paisagem do Rio de Janeiro. Nesse sentido, procuramos demonstrar o quão entrelaçadas estão as florestas com a urbe carioca, sendo compreendidas como sistemas socioecológicos (SSE). Por fim, na terceira sessão aprofundaremos uma discussão sobre a dicotomia espécie nativa $\times$ espécie exótica, que se apresenta como um subcomponente da dicotomia natureza $\times$ cultura. Para materializar essa discussão, a história ambiental de uma espécie exótica e emblemática nas florestas urbanas do Rio de Janeiro será destrinchada: a árvore frutífera jaqueira.

\section{Os paleoterritórios da Mata Atlântica}

Nos últimos 500 anos os ecossistemas brasileiros passaram por grandes transformações, a Mata Atlântica sendo um dos biomas que mais sofreu com essas mudanças. Portanto, é notável o legado socioecológico impresso na paisagem da Mata Atlântica por atividades econômicas como as monoculturas de cana-de-açúcar e café. A configuração atual desse bioma compreende extensas áreas desmatadas, encostas desnudas, rios assoreados e remanescentes florestais praticamente restritos a terrenos declivosas e de difícil acesso, sob a forma de florestas secundárias de diferentes idades e trajetórias sucessionais (OLIVEIRA; SOLÓRZANO, 2OI4). Apesar de grande parte da perda de cobertura vegetal na Mata Atlântica poder ser retraçada ao empreendimento colonial português, a floresta que foi sucessivamente explorada e desmata não era pristina: "o uso da técnica e, particularmente, o controle do fogo deram às populações précoloniais uma potencial capacidade de alterar o meio" (OLIVEIRA; SOLÓRZANO, 20I4).

Três hipóteses podem explicar o papel da presença histórica do homem na Mata Atlântica com legados que deixaram evidências na própria biodiversidade. Uma das hipóteses está relacionada aos primeiros grupamentos humanos que habitaram o bioma. Devido à relativa escassez de biomassa vegetal comestível a caça se tornou a principal fonte de alimento, o que provavelmente levou à tamanha pressão sobre a fauna e, em consequência, à extinção de algumas espécies. No final do pleistoceno, algumas espécies de mega-herbívoros viviam no domínio atlântico, e sua extinção é atribuída sobre caça. Uma segunda hipótese está relacionada às populações nativas mais recentes que, através da técnica de agricultura de corte-e-queima, foi responsável por domesticar as paisagens florestadas da Mata Atlântica, selecionando espécies 
cultivares e produzindo um mosaico de florestas secundárias em diferentes estágios de sucessão. Essa técnica foi também adota por populações costeiras mais modernas, conhecidas como caiçaras, e outros sitiantes locais até o final do século XX. Por fim, as necessidades energéticas das metrópoles emergentes desde o início do período colonial e, posteriormente, o avanço da industrialização e urbanização, geraram demanda por uma fonte barata e abundante: o carvão vegetal. Produzido nas baixas encostas das florestas ombrófilas densas do Sudeste, as carvoarias, que eram o lócus de produção in situ, deixaram vestígios nítidos, tanto na morfologia quanto na estrutura e na composição da paisagem. Essas três hipóteses apresentam evidências materiais impressas na paisagem florestal dos remanescentes de Mata Atlântica. A ausência de uma megafauna denota consequências diretas na fisionomia e na estrutura mais densa e fechada da vegetação. A agricultura de corte-e-queima, praticada até recentemente, deixou um legado impresso na composição de espécies e no mosaico sucessional dos remanescentes atuais. A técnica artesanal de produção de carvão, que selecionava espécies e indivíduos pelo tamanho, levou a mudanças na composição de espécies, mas permitiu a rápida recomposição da estrutura da vegetação (OLIVEIRA; ENGEMANN, 2OII; OLIVEIRA et al., 2OI2; OLIVEIRA; SOLÓRZANO, 20I4).

A história de ocupação do Rio de Janeiro não se resume aos 450 anos de sua fundação como cidade. Antes disso, há milhares de anos, populações de paleoíndios sambaquieiros que viviam da caça e da coleta já ocupavam o litoral carioca (OLIVEIRA, 2OI2). Posteriormente a essa primeira leva de ocupação vieram outras tradições indígenas (caçadores e agricultores), os colonizadores europeus e a vasta população de escravos africanos que tiveram um papel fundamental na transformação da paisagem da cidade que vemos hoje, apropriando-se de maneira única deste território. Depois de quase 500 anos de uso, ocupação e transformação da paisagem, o Rio de Janeiro tornou-se uma metrópole global com poucos remanescentes de floresta que permeiam a paisagem da cidade.

Os maciços costeiros do Rio de Janeiro foram palco de um extenso processo de uso dos recursos florestais por antigas populações de escravos e ex-escravos para a produção de carvão como meio de subsistência. Esse trabalho, em grande parte invisível aos olhos da sociedade, permitiu o estabelecimento dessas populações marginalizadas dentro da floresta formando pequenas populações quilombolas (FRAGA; OLIVEIRA, 2OI2). O auge da produção se deu entre os séculos XIX e XX, após o declínio das monoculturas e da abolição do trabalho escravo.

O espaço apropriado pelo trabalho e impresso com a identidade dos carvoeiros constituíram territórios dentro da floresta e que deixaram um legado socioecológico na paisagem, na forma de paleoterritórios dos carvoeiros (OLIVEIRA, 2007). Por definição, esses paleoterritórios participam da dinâmica successional da floresta, em que a maneira que o carvoeiro transforma a biomassa contida na vegetação em energia na forma de carvão, deixa um legado ecológico registrado na estrutura e na composição da vegetação, além de alterar fisicamente o terreno criando platôs em áreas de encosta e deixando vestígios materiais como ferramentas e ruínas de 
antigas habitações (OLIVEIRA, 2007). Esses paleoterritórios deixaram escondidos sobre a densa cobertura das florestas urbanas do Rio de Janeiro I.I76 sítios de fornos de carvão abandonados (carvoarias), I28 ruínas, incluindo antigas habitações e fazendas, e sistemas de captação de água (SOLÓRZANO et al., 2015, 2018).

\section{O papel das florestas urbanas nos sistemas socioecológicos}

Um dos maiores trechos florestais urbanos do mundo está localizado em um maciço montanhoso na parte central dessa metrópole, e atualmente abrange uma unidade de conservação: o Parque Nacional da Tijuca (PNT). Longe de ser um remanescente de natureza intocada, essa área protegida é coberta principalmente por florestas secundárias que naturalmente se regeneraram, ou foram reflorestadas, em terras anteriormente usadas para agricultura, habitação humana, fonte de energia e abastecimento de água, entre outros propósitos.

Para melhor entender o grau de entrelaçamento entre a dimensão humana e a dimensão ecológica no Rio de Janeiro é necessário estabelecer uma conexão direta com a perspectiva da Teoria de Sistemas. Estes dois componentes - sociedade e natureza - são vistos como partes de um todo mais complexo, agora conhecido como sistemas socioecológicos (SSE). Nesse sentido, um sistema socioecológico pode ser definido como:

[...] um sistema complexo e adaptativo que consiste em uma unidade biogeofísica e seus atores sociais e suas instituições associadas. Os limites espaciais ou funcionais do sistema delimitam determinado ecossistema particular e seu contexto de problemas. (GLASER et al., 2012, p. 4, tradução nossa). ${ }^{4}$

Compreender esses sistemas socioecológicos é uma parte importante da pesquisa social nos dias atuais, pois os resultados de interações homem-ambiente do passado têm implicações para o futuro comum da humanidade. Assim como o conceito de ecossistema, o sistema socioecológico pode ser aplicado e entendido em múltiplas escalas, tendo sua existência concreta apenas manifestada na paisagem, como, por exemplo na Floresta da Tijuca, uma floresta urbana no Rio de Janeiro e importante remanescente da Mata Atlântica.

As florestas urbanas do Rio de Janeiro são compostas por mosaicos de trechos de diferentes idades e graus de conservação, com a sobreposição de diversos usos pretéritos que produziram uma paisagem complexa resultante da relação de culturas ao longo de séculos de ocupação e uso (OLIVEIRA et al., 20II; FERNANDEZ, 20I2;). Do ponto de vista socioecológico, as florestas remanescentes da cidade constituem ecossistemas mesclados de espécies nativas e exóticas constituintes de espaços apropriados e modificados pelo homem. Atualmente, essas florestas urbanas estão em um processo de transformação cada vez mais dinâmico na medida em que as relações socioeconômicas da rede urbano-metropolitana recriam antigos processos de uso do solo

\footnotetext{
4 "A social-ecological system is a complex, adaptive system consisting of a bio-geo-physical unit and its associated social actors and institutions. The spatial or functional boundaries of the system delimit a particular ecosystem and its problem context" (GLASER et al., 2012, p. 4).
} 
e criam novas formas de ocupação produzindo novos ecossistemas (isto é, ecossistemas emergentes ou neoecossistemas sensu, HOBBS et al., 2013 $3^{5}$ e outras categorias de uso do solo derivadas de distintas relações socioecológicas. Portanto, ao estudar a paisagem, podemos perceber a reprodução de valores culturais de cada período histórico, impressos na forma, na estrutura e na composição, criando rearranjos espaciais das populações humanas e das demais espécies.

A partir da fundação do Rio de Janeiro, em 1565, foram conduzidos diferentes tipos de atividades econômicas, desde pequenas e isoladas áreas de agricultura e pecuária familiar até vastas regiões de monoculturas (cana-de-açúcar e café), contando com a extração de lenha e a produção de carvão, principal fonte energética durante séculos na cidade. A sobreposição histórica desses usos e dessas formas de ocupação da paisagem por esses agentes sociais gerou um legado socioecológico, em grande parte escondido sob a cobertura vegetal remanescente (OLIVEIRA; SOLÓRZANO, 20I4; SOLÓRZANO et al., 2015).

Pode-se dizer que a história de ocupação da vertente sul do Maciço da Tijuca, localizado na zona sul da cidade do Rio de Janeiro, inicia-se com a fundação do Engenho Real, em I575 (depois conhecido como Engenho d'El Rei, ou Engenho do Salema, ou Engenho da Lagoa, ou Engenho de Nossa Senhora da Conceição, ou Engenho do Fagundes). Dez anos após o início da ocupação précolonial da Cidade Velha (1565), incentivado pela Coroa Portuguesa, Antônio Salema governador do Rio de Janeiro, instalou o primeiro engenho de açúcar nas margens da Lagoa de Sacopenapã hoje Rodrigo de Freitas (ABREU, 20IO).

Destacamos a atividade de produção de cana-de-açúcar entre os séculos XVI e XVIII, que contou com o uso de recursos madeireiros provenientes do manguezal existente nas margens da lagoa e das florestas de encostas com o objetivo de produção de lenha para alimentar os fornos; de construção de cercas (para o gado e para a população de muares e equinos); e de construção das caixas para transporte de açúcar, carros de boi, madeiramento das casas e ferramentas diversas (ENGEMANN et al., 2005). Assim, percebe-se que os engenhos localizados na vertente sul do Maciço da Tijuca teriam demandado quantidade significativa da cobertura florestal.

Com o desmonte do Engenho d'El Rei no início do século XIX, incialmente para o estabelecimento da Real Fábrica de Pólvora, e posteriormente sendo loteado e fragmentado em sítios e chácaras de veraneio, o padrão de uso e ocupação muda significativamente (BARATA; GASPAR, 20I5). É precisamente nesse período que podemos traçar a entrada da jaqueira ${ }^{6}$

\footnotetext{
${ }^{5}$ Um novo ecossistema é composto por componentes abióticos, bióticos e sociais (e suas interações) que por virtude de influência humana, difere daqueles que prevaleceram historicamente, tendo uma tendência a auto-organização e manifestam novas qualidades sem o manejo humano. Novos ecossistemas são diferentes dos ecossistemas híbridos e separados por limites práticos (uma combinação de limiares ecológicos, ambientais e sociais) da recuperação de qualidades históricas (HOBBS et al. 2013).

${ }^{6}$ Artocarpus heterophyllus Lam. é uma espécie da família Moraceae (mesma família das figueiras) e é conhecida popularmente no Brasil como jaqueira ou jaca. Seu nome é advindo do grego ártos, que significa alimento; karpós, fruto; e heterophyllus, diferentes folhas; fazendo alusão às folhas com bordas inteiras na árvore adulta e recortadas nos indivíduos juvenis - i.e. heterofilia. A espécie tem uma possível distribuição original em florestas sempre verdes em gradientes altitudinais entre 400 e 1.200 metros na região denominada Western Ghats,
} 
(Artocarpus heterophyllus Lam.) nesse complexo sistema socioecológico composto pelos territórios dos atores sociais locais interagindo com a floresta, que já não era virgem ou intocada. Encontramos evidencias desse legado cultural das jaqueiras usadas como árvores de jardim e pomares em uma das chácaras remanescentes dessa região: Solar Grandjean de Montigny. Atualmente, podem ser observados exemplares de jaqueira e mangueira com diâmetros superior a um metro e alinhados na disposição de um antigo pomar (SOLÓRZANO et al., 20I8).

Devido à popularidade da jaqueira como espécie ornamental e frutífera, podemos supor que muitas, se não todas, as chácaras dessa região contavam com populações de jaqueira em sua propriedade. Os territórios dessas antigas chácaras hoje fazem parte dos bairros da Gávea, do Jardim Botânico e do Humaitá, ocupando, em grande parte, as áreas de contato entre a malha urbana e a atual cobertura vegetal remanescente da Floresta da Tijuca. E é justamente nessa área de contato que se desenvolveu o que atualmente chamamos de neoecossistema em ambiente de borda. Esse neoecossistema apresenta uma das maiores densidades e dominâncias de população de jaqueira da Floresta da Tijuca. Está situado especificamente no setor Serra da Carioca do Parque Nacional da Tijuca, na borda de uma área conhecida como Horto Florestal.

Existe uma crescente tendência em reconhecer que, uma vez "deixados sozinhos", ecossistemas modificados pelo homem não retornam ao seu estado primitivo. Recentemente essa noção tem sido defendida por um grupo de ecólogos que propõe o conceito de ecossistemas "emergentes" ou "neoecossistemas". Ecossistemas emergentes são o resultado direto ou de uma intensa modificação humana de ecossistemas preservados, ou do abandono de áreas com uso do solo bem estabelecido (lavouras, pastagens, florestas plantadas etc.). Esses ecossistemas apresentam localmente padrões inéditos de composição e dominância de espécies que não dependem da intervenção humana para sua manutenção e que tenham atravessado algum tipo de limiar socioecológico (HOBBS et al., 2006; HALLET et al., 2013).

Conforme foi descrito anteriormente, a cidade do Rio de Janeiro teve uma grande demanda por carvão na construção civil, especialmente cantaria, consumido para uso doméstico e industrial, a fim de alimentar as locomotivas e em várias vendas que produziam ferramentas de metal. Assim, o carvão vegetal foi a principal fonte de energia para o crescimento da cidade no século XIX e o único material disponível para a produção de ferro do país até o final do século XX (SOLÓRZANO et al., 20I5). O Maciço da Tijuca abrigou a atividade de produção de carvão, especificamente nas vertentes sul, tendo sua produção escoada através de sistema de caminhos, trilhas e estradas, e que atualmente foi incorporado na Trilha Trasncarioca, que recorta todo o PNT (SOLÓRZANO et al., 2OI8).

Recentemente foi verificada uma grande sobreposição espacial da distribuição da jaqueira com vestígios de uso e ocupação humana da floresta, revelando uma íntima relação da cultura

na Índia (DE CANDOLLE, 1886 apud THOMAS, 1980; JARRET, 1959; MORTON, 1965), onde é considerada rara, apresentando poucos indivíduos por área (CHITTIBABU; PARTHASARATHY, 2000). 
carioca com a jaqueira (SOLÓRZANO et al., 20I8). Em vez de invadir a floresta pristina, a jaqueira ocupa os espaços abertos pelas atividades humanas, particularmente pelas populações que dependiam da floresta para obter sustento e moradia. Carvoeiros, comunidades periurbanas e moradores das bordas da floresta interagiram de maneira complexa e adaptativa com a floresta. A jaqueira foi aclimatada no Jardim Botânico(BEDIAGA, 20I4) pelo seu potencial valor comercial e domesticada para fins de alimentação e ornamentação nas chácaras periurbanas, bem como foi introduzida nas áreas de borda da floresta, nos lócus de produção de carvão e nas moradias na floresta. Desse modo, é um componente importante do sistema socioecológico floresta-cidade do Rio de Janeiro, atualmente indicando na paisagem florestal os espaços marcados pela história e pela cultura da sociedade carioca.

\section{A história de introdução e domesticação da jaqueira na Mata Atlântica}

A domesticação da jaqueira é datada de um passado remoto, sendo até hoje uma das espécies mais usadas nos trópicos (THOMAS, I980). Theophrastus, em 300 a.C., falou sobre a espécie: "Há uma outra enorme árvore que possui frutos maravilhosamente doces e grandes; esta é usada como alimento por monges da Índia" (JARRET, I959). Segundo Calazans (2005), a ligação mais antiga da espécie à cultura humana remonta à civilização Harappā durante o período entre 2.500 e I.O00 a.C., na atual região localizada entre o Paquistão e o noroeste da Índia. Para aquela civilização, a espécie era símbolo do início do verão, ao que se faz provável referência à época de maior intensidade de produção de frutos desta planta.

Acredita-se que a espécie já era cultivada nas Filipinas durante o século XII (PELZAR, 1948 apud HAQ, 2006). Seu cultivo se espalhou para diversos países asiáticos; incluindo Bangladesh, Nepal, Sri Lanka, China, Vietnã e outros, e daí para a África tropical (MORTON, 1965). A partir de meados do século XVII até o século XIX, a espécie já podia ser encontrada na América tropical e subtropical (Brasil, Suriname, Caribe e Estados Unidos) e Austrália (FERRÃO, I992).

Sabe-se que a jaqueira é historicamente utilizada para alimentação de homens e animais, seu potencial calórico e sua facilidade de cultivo em todas as regiões tropicais foram altamente explorados durante o processo de expansão colonialista, facilitado pelas grandes navegações (CHAVES et al., I966; CORRÊA, I984; FERRÃO I992). Esse processo permitiu a introdução da jaqueira nas colônias tropicais da América e da África, as quais, subordinadas à Coroa portuguesa, deveriam receber dos vice-reis da Índia as plantas de interesse comercial para viabilizar seu cultivo, a partir da aclimatação a ser realizada (FERRÃO, I992).

A jaqueira participou de um plano de experimentação agrícola com que a Coroa portuguesa, em uma época de baixa dos preços internacionais do açúcar, tentou reformular sua economia imperial. Lançado em I680, o plano visava introduzir na América do Sul espécies asiáticas com potencial valor comercial no mercado europeu. Capital da outrora extensa rede de feitorias que os portugueses mantinham, parcialmente, no final do século XVII, no sul e no sudeste asiáticos, a cidade de Goa foi a mediadora na transferência de espécimes e conhecimento técnico para 
Salvador, na Bahia, que atuou como agente redistribuidor (SOLÓRZANO et al., 2015). Como as sementes da jaqueira, desidratando-se, perdem a capacidade de germinar em no máximo 60 dias (SILVA et al., 2007), a transferência precisava ser feita por meio de mudas (nos veleiros da época, a viagem de Goa a Salvador não durava menos de seis meses). Uma das primeiras levas veio no navio S. Francisco Xavier, que chegou a Salvador em I683, trazendo 35 a 40 mudas, acompanhadas de instruções sobre o plantio (ANTHONY, 2OI3).

Uma das primeiras descrições da jaqueira "baiana" foi feita no final do século XVIII por Luís dos Santos Vilhena. Ele fala de uma árvore "monstruosa", de "madeira rijíssima e revessa"; de seu tronco pendiam "frutos monstruosos", cuja casca extremamente áspera abrigava "bagos cobertos de polpa comestível e [...] muito doce". Vilhena conta que dessa fruta se serviam sobretudo os pobres, "pois que se vende em talhadas de que podem comprar, à proporção do dinheiro que tem" (VILHENA, I969, p. 7II). Além de alimentar os menos abastados, sua madeira apresentava propriedades interessantes para a construção naval. Como não se oxidava em contato com metais, o lenho da jaqueira era adequado à fabricação dos cavernames das embarcações, peças curvas fixadas transversalmente na quilha (HUTTER, 2005).

A jaqueira tem múltiplos usos, podendo ser utilizada como alimento, madeira, corante, combustível e até mesmo como medicamento (SCUC, 2006). Como recurso alimentar, a espécie apesenta um valor energético significativo: a polpa do fruto - uma de suas partes comestíveis - é composta de $72 \%$ de água, sendo rica em proteínas, carboidratos, fibras, cálcio, fósforo, sódio, potássio, entre outros elementos (MORTON, 1965). Esse potencial de uso relacionado à alimentação foi e ainda é uma justificativa mais do que razoável à introdução da espécie em diversas partes do mundo onde o cultivo é favorecido pelo clima.

A espécie também se popularizou como árvore ornamental e frutífera de quintais e jardins. Tornou-se presença marcante nas chácaras - residências de veraneio que nobres rurais e ricos comerciantes mantinham - na periferia das principais metrópoles como o Rio de Janeiro. Um século e meio depois de chegarem as primeiras mudas, Charles Darwin observou a predileção pela espécie nas paisagens periurbanas de Salvador. O naturalista anotou em seu diário que a paisagem dos arredores de Salvador "quase tira o seu caráter [da jaqueira e da mangueira]" (DARWIN, I909, p. 42, grifo nosso).

A adaptação ao ambiente da Mata Atlântica foi tão boa que os contemporâneos, sem a preocupação atual com a "indigeneidade" das espécies, tratavam a jaqueira como uma árvore tão brasileira quanto asiática. Os dicionários do final do século XVIII, a exemplo do de Moraes Silva, assinalam, no verbete "Jaca", que se trata de uma "fruta Asiática e Brasileira", sem distinção (MORAES SILVA, I789, p. 740). Segundo Pio Correa (1984), houve botânicos que chegaram ao ponto de classificá-la como Artocarpus brasiliensis. Destacam-se também os relatos de Bernardino Antônio Gomes, médico pela Universidade de Coimbra que esteve no Brasil entre I797 e I80I (VELLOSO, 2007) como médico da Armada Real e, deslumbrado com a flora deste país, principalmente ao que se refere às espécies para fins medicinais, publicou suas "Observações 
botanico-medicas sobre algumas plantas do Brasil" nas Memórias da Academia Real das Sciências de Lisboa, em I8I2. Tal publicação, na qual se reúnem I5 espécies ditas brasileiras pelo autor, ele faz referência a exemplares da espécie Artocarpus brasiliensis (VELLOSO, 2007). Nota-se a importância da jaqueira, incluída dentre as 15 plantas escolhidas para serem retratadas nas observações de Bernardino Gomes sobre a flora brasileira. Evidenciando que a espécie já se encontrava, naquela época, naturalizada no Brasil de tal forma que era considerada membro de sua flora. Essa naturalização se deve, em grande parte, pela popularidade da espécie no século XIX, devido ao seu elevado valor pelos múltiplos usos que apresenta, mas também pelo seu sucesso adaptativo às condições ambientais encontradas nas florestas de terras baixas e submontanas da Mata Atlântica. Cabe ressaltar aqui, que essa percepção da jaqueira ser naturalizada ou até nativa perdura para uma parcela significativa da população, principalmente em comunidades vivendo em contatos com as jaqueiras, nas bordas ou no interior de florestas em áreas urbanas e periurbanas que a utilizam como recurso alimentar. A visão dominante por ambientalistas e conservacionistas de a jaqueira ser exótica e invasora, é algo historicamente mais recente e que ganhou corpo apenas nas últimas décadas com estudos sobre a dinâmica populacional da espécie em uma floresta urbana do Rio de Janeiro (ABREU; RODRIGUES, 20Io).

Não se sabe exatamente quando a jaqueira foi introduzida no Rio de Janeiro, mas há fortes indícios de que isso tenha acontecido nos anos 1780. Chaves et al. (I967 apud ABREU; RODRIGUES, 20I0) afirmam que já havia indivíduos "naturalizados" no Rio de Janeiro em I803. Essa introdução inicial estaria associada tanto ao caráter de recurso alimentar para alimentação da população escrava e do gado empregados nos engenhos e nas fazendas quanto pelo valor ornamental e frutífero incorporado nas chácaras das áreas periurbanas do Rio de Janeiro (CORRÊA, 1984; SOLÓRZANO et al., 2016).

Mais de dois séculos depois da sua introdução inicial, a jaqueira encontra-se amplamente distribuída pelos remanescentes florestais do Rio de Janeiro. No recém-lançado Inventário da cobertura arbórea da cidade do Rio de Janeiro (RIO DE JANEIRO, 2015), a jaqueira figura entre as cinco espécies mais importantes, levando em consideração sua abundância, o tamanho dos indivíduos (muitos centenários e de grande porte, isto é, $>50 \mathrm{~cm}$ de DAP, diâmetro à altura do peito) e a distribuição pela cidade. O relatório destaca que:

A grande ocorrência de jaqueiras, deve-se, principalmente ao grande número dessa espécie no PEPB (Parque Estadual da Pedra Branca), Mendanha, adjacências do PNT (Parque Nacional da Tijuca) e áreas antropizadas, onde em antigas fazendas, bordas de florestas e áreas perturbadas ocorrem reboleiras e grandes indivíduos isolados. (RIO DE JANEIRO, 2015, p. 86)

A reconstrução da história ambiental das florestas urbanas cariocas tem mostrado um elevado grau de entrelaçamento entre a história de uso e ocupação das florestas com o padrão de distribuição espacial dessa espécie. As evidências de sobreposição de uso e associação espacial da jaqueira, complexifica o entendimento de paleoterritório. Como a jaqueira foi uma espécie 
frutífera introduzida para alimentação da população escrava, ela foi devidamente apropriada e incorporada na alimentação dos carvoeiros. Um alimento rico em carboidrato e proteína e de baixo custo foi transportado para as áreas de seu trabalho na floresta, germinando dos restos não consumidos e descartados na floresta. Não pode ser descartada a hipótese de que os carvoeiros introduziram intencionalmente as jaqueiras em locais de exploração de carvão e ao longo das trilhas para ser aproveitadas em futuras investidas na mata. Assim, a jaqueira representa um legado da presença humana na floresta, como um elemento cultural que compõe o SSE da Floresta da Tijuca, o que vem sendo classificado como neoecossistema. Essa visão, estabelecida dentro da perspectiva interdisciplinar de sistemas socioecológicos, vai muito além de olhar a jaqueira como simples espécie exótica invasora, o que reduz seu papel ecológico atual, seu legado histórico e seu valor cultural.

\section{Quando valorizar uma espécie exótica virou uma polêmica ambientalista?}

A narrativa aqui exposta é sobre a história de uma espécie nativa da Ásia e seus atributos culturais, bem como sobre a domesticação dessa espécie frutífera que foi disseminada e valorizada em diferentes partes do mundo. Uma vez introduzida no território brasileiro, a jaqueira ganhou contornos particulares ao interagir com a população local e com os ecossistemas nativos. Portanto, a história que se destaca é justamente sobre como o ser humano interage com outras espécies, e como essa relação muda ao longo do tempo. A civilização ocidental se espalhou pelo mundo e redistribuiu diferentes espécies pelo globo reorganizando as dinâmicas ecológicas do planeta. Nesse sentido, é importante ir além de uma visão dualista ou maniqueísta sobre as diferentes espécies que compõem a paisagem. Ir além de um dualismo simplista de exótico $x$ nativo, que em grande parte se sustenta na dicotomia homem $\times$ natureza, que por sua vez se respalda na falaciosa noção declensionista de que o ser humano é o grande destruidor e vilão da natureza. A humanidade, sim, apresenta um lado ganancioso e destruidor que remove completamente a cobertura vegetal para implementar um sistema de monocultura para lucrar em um sistema quebrado e insustentável socioecologicamente. Mas é evidente que existem outros caminhos possíveis, que na verdade sempre existiram aqui mesmo na Mata Atlântica. Narrativas que sustentam a possibilidade de o ser humano coexistir com outras espécies, mesmo delas tirando seu sustento e transformando a paisagem. Possibilidades de manejo e codomesticação de espécies e paisagens, desenvolvendo relações mutuamente benéficas. Assim, apresentamos uma crítica ao ambientalismo moderno, que revela claras defasagens em face do entendimento das dinâmicas socioespaciais e socioecológicas, históricas e contemporâneas.

Desenvolvemos aqui uma narrativa baseada em investigação de campo que permitiu ir além do estabelecido e compreender melhor como uma cultura transformou o espaço e produziu uma paisagem repleta de marcas da sua história impressas na estrutura física, no substrato e na própria vegetação. Nessa história de transformação da paisagem, as espécies exóticas têm um papel importante na narrativa central: ser um indicador da ação humana no espaço ecológico, e também 
protagonizar as próprias conexões na paisagem, se mantendo e reproduzindo no espaço sem o manejo humano. Talvez esse seja um dos pontos nevrálgicos, a dinâmica ecológica que foge do controle do manejo humano. Em situações em que espécies exóticas são introduzidas em um novo ambiente, e que começam a apresentar uma dinâmica própria, se reproduzindo e mantendo populações viáveis, muitas vezes é caracterizado como uma espécie invasora. Esse termo é bastante utilizado nas ciências biológicas, em um ramo específico que estuda esse tipo de situação chamado biologia da invasão, conceito desenvolvido por Elton (1958). Vejo aqui um conceito recheado de subjetividade, mas que passou a ser visto como uma verdade científica, escondendo o fato de que no fundo é uma maneira de se classificar o comportamento de uma espécie. E, como sabemos, toda classificação tem algum grau de subjetividade, pois depende das categorias estabelecidas pelo o autor. E como se classifica o comportamento de espécies vegetais, utilizando categorias fundamentalmente humanas? Fica evidente que foi a cultura portuguesa a invasora dos territórios das populações nativas que viviam no domínio do bioma Mata Atlântica. As plantas que trouxeram foram meros coadjuvantes nessa narrativa de invasão territorial, e não as protagonistas. Mas recai sobre elas os ônus da invasão e da destruição dos ecossistemas nativos. E a narrativa estabelecida no ambientalismo moderno é bem clara: tudo que é de fora, estrangeiro, exótico, alienígena, não é bom. E fundamentalmente não é bom por que nos remete a uma cultura que veio de fora e invadiu, ou seja, nos faz lembrar o lado negativo da cultura invasora. Ser exótico logo virou sinônimo de ser invasor, o que é o pior rótulo que uma espécie pode receber, pois justifica a racionalidade por trás de movimentos de erradicação e manejo radical. Tudo isso em prol de uma natureza intocada. Uma noção que há muito se construiu de que natureza é onde o ser humano não está; lógica dicotômica que apenas reforça uma ruptura do ser humano com as outras espécies e com o ambiente físico.

\section{Considerações finais}

O diálogo entre os campos da Geografia, da Antropologia, da História e da Ecologia tem trazido à tona novas perspectivas sobre antigos conceitos de natureza e cultura, espécies nativas e exóticas. A paisagem retém na sua estrutura e na sua composição evidências das histórias ambientais impressas pela sociedade. As espécies exóticas contam ricas narrativas sobre traços específicos da cultura material das populações que interagiram e interagem com a floresta. Nessa perspectiva, a geografia histórica da jaqueira se entrelaça com a ecologia histórica das florestas urbanas, e revela a conexão da cultura com a floresta. Entender como a paisagem foi usada, sendo estabelecidos territórios e estes ocupados por diferentes populações, é fundamental para quebrar uma lógica de invasão transposta para o comportamento de uma espécie introduzida intencionalmente no sistema socioecológico, exercendo múltiplos papéis e oferecendo uma série de serviços ecossistêmicos para a comunidade. Assim, a ecologia histórica se posiciona como uma ferramenta importante para ser aplicada à resolução de problemas concretos e proposição de políticas públicas relacionadas aos sistemas socioecológicos, ao manejo de espécies exóticas e à restauração das florestas. 
Existem diferentes olhares sobre o papel dessa espécie, variando de mutuamente benéfico a invasor:

(I) Sob a perspectiva de conservação da biodiversidade a jaqueira é classificada como espécie exótica invasora e indesejável para a floresta, suprimindo a presença de espécies nativas por exercer uma pressão por propágulo (ABREU; RODRIGUES, 20IO). Nessa perspectiva, destaca-se a importância do manejo ou até a erradicação das populações de jaqueira em áreas de unidade de conservação.

(2) Em uma perspectiva funcionalista da paisagem, a jaqueira pode ser considerada como provedora de serviços ecossistêmicos, como regulação de fluxos hidrológicos, cobertura arbórea, proteção do solo, sequestro de carbono e resiliência da biomassa e recurso alimentar para a fauna. Essa perspectiva ganha um destaque na medida em que estudos recentes mostram a importância da regeneração natural de florestas secundárias em escala regional como um componente importante da resiliência da biomassa desses ecossistemas (POORTER et al., 20I6). Assim, deve ser ampliado o conceito de regeneração natural para incluir espécies exóticas, já que fazem parte do patrimônio local e regional de espécies compondo esses sistemas socioecológicos.

(3) A dimensão cultural e simbólica aprofunda o entendimento da paisagem geográfica, estabelecendo conexões entre a diversidade cultural e biológica (UNESCO-SCBD, 20I4). Assim, a jaqueira apresenta uso simbólico e ritualístico pela tradição afro-brasileira. No candomblé, a jaqueira é considerada sagrada e representa Apaoká, uma entidade de culto secreto e complexo, referida como a mãe de Oxóssi (AZEVEDO, 2015). Além disso, é uma importante fonte de alimento (rico em proteína, carboidrato e açúcares) para comunidades de borda das florestas, gerando segurança alimentar e ampliando a resiliência socioecológica.

(4) Na perspectiva agroflorestal e da agricultura sintrópica (ANDRADE; PASINI, 20I4), a jaqueira é considerada espécie de estrato superior, que produz grande quantidade de matéria orgânica, de rápido estabelecimento e crescimento, e com produção de grande quantidade de frutos. Existe ainda a possiblidade de beneficiamento e comercialização para mercado crescente de alimentação agroecológica (vegano, orgânico, autossustentável) ou para a produção de farelo para ração (ainda subaproveitado) e com uma crescente valorização em mercados externos (Europa, Estados Unidos e Ásia).

(5) Na esfera jurídica que rege o Sistema Nacional de Unidade de Conservação (SNUC), a jaqueira é considerada uma espécie exótica e com potencial invasor, sendo implementados programas de manejo para sua erradicação na gestão do território das UCs de proteção integral.

O paradigma de novo ecossistema desloca as preocupações da gestão do objetivo único em manter ou recuperar ecossistemas históricos, em direção a uma maior consideração qualitativa de como os ecossistemas funcionam para fornecer o habitat das espécies e importantes serviços ecossistêmicos incluindo lugares para se conectar com a natureza, fontes de água potável e recursos para meios de subsistência locais (YUNG et al., 20I3). Na medida em que assembleias de 
espécies são modificadas e se adaptam a mudanças socioecológicas na paisagem, pode haver instâncias em que neoecossistemas sejam preferíveis a qualquer ecossistema histórico (HALLET et al., 2OI3). O conceito de novo ecossistema fornece um quadro importante para os gestores que lidam com a definição de metas de restauração e intervenção em um mundo em mudança. Especificamente, ele ultrapassa o limite conceitual de sempre tentar retornar a alguma referência de ecossistema histórico. No entanto, a utilidade do termo depende da extensão em que o grau de novidade pode ser avaliado e se existem limiares entre os estados do ecossistema que podem ser medidos (HARRIS et al., 2OI3). Por fim, o conceito de novos ecossistemas poderia remodelar a forma como pensamos sobre conservação, nossas interações com a natureza e o diálogo público sobre gerenciamento de ecossistemas (YUNG et al., 20I3).

O framework de sistemas socioecológicos contribui com um paradigma que rompe com a dicotomia sociedade $\times$ natureza. Nesse sentido, sociedade e natureza, que tradicionalmente são consideradas como unidades separadas e até opostas, passam a ser entendidas como subcomponentes de um todo, em uma perspectiva sistêmica, ou seja, mais do que a pura soma das partes. Quais seriam as propriedades emergentes desse sistema? O entendimento de que cada elemento do sistema tem um papel, e que esse papel está interconectado com outros elementos. $\mathrm{Na}$ perspectiva de sistemas socioecológicos (SSE), a conservação da biodiversidade é um componente importante e que medeia a interação humana com outros organismos. Da mesma maneira, devem ser valorizadas a riqueza cultural e de práticas de subsistência humana, as quais tecem a maneira como as interações socioecológicas são realizadas. Em uma perspectiva histórica, as múltiplas interações socioecológicas estão registradas na paisagem que vemos hoje através das memórias impressas na estrutura e na composição da vegetação. Esses legados culturais socioecológicos expressam a riqueza da história de transformação que a humanidade gerou em determinado espaço-tempo. A diversidade biocultural de uma paisagem, assim como preconizada pela Florence Declaration on the Links between Biological and Cultural Diversity (UNESCOSCBD, 2OI4), deve ser considerada como essencial dos SSE, ampliando as possibilidades de conservação da biodiversidade. Essa declaração da UNESCO-SCBD destaca a importância de se ampliar pesquisas interdisciplinares e transdisciplinares que investiguem as ligações entre diversidade biológica e diversidade cultural na escala da paisagem. Assim, existe um equilíbrio a ser encontrado entre aquilo que classificamos como espécies nativas e exóticas, compondo um patrimônio de espécies existentes em um SSE. Considerando os conhecimentos produzidos pelas diversas ciências que estudam a dimensão sociedade $\times$ natureza, devem ser desenvolvidas, aprofundadas e aplicadas outras classificações para as espécies não nativas, como naturalizadas, oportunistas, funcionais e úteis, que possibilitam outras maneiras de entender seu papel nos sistemas socioecológicos. 


\section{Referências}

ABREU, M. A. Geografia histórica do Rio de Janeiro(I5O2-I7OO). Rio de Janeiro: Andrea Jakobson Estúdio, 2010.

ABREU, R. C. R.; RODRIGUES, P. J. F. P. Exotic tree Artocarpus heterophyllus (Moraceae) invades the Brazilian Atlantic Rainforest. Rodriguésia. v. 6I, n. 4, p. 677-688, 2010.

ANDRADE, D. V. P., PASINI, F. S. Implantação e manejo de agroecossistema segundo os métodos da agricultura sintrópica de Ernst Götsch. Cadernos de Agroecologia, v. 9, n. 4, 2014.

ANTHONY, P. S. Relações intracoloniais: Goa - Bahia, I675-I825. Brasília: FUNAG, 2013.

AZEVEDO, V. A. M. Ewé Igbo: árvores sagradas do candomblé no contexto socioambiental. 2015. I32f. Dissertação (Mestrado em Ensino de Ciências, Ambiente e Sociedade) - Faculdade de Formação de Professores, Universidade do Estado do Rio de Janeiro, Rio de Janeiro, 2015.

BALÉE, W.; ERICKSON, C. Time, complexity, and historical ecology. In: BALÉE, W.; ERICKSON, C. (Eds.). Time and complexity in historical ecology: studies in the neotropical lowlands. New York: Columbia University Press, 2006.

BARATA, C. E. A.; GASPAR, C. B. A Fazenda Nacional da Lagoa Rodrigo de Freitas. Rio de Janeiro: Editora Cassará, 2015.

BEDIAGA, B. Marcado pela própria natureza: o imperial instituto fluminense de agricultura - I860 a I89I. Rio de Janeiro: FGV Editora, 20I4. 236p.

CABRAL, D. C.; SOLÓRZANO, A.; OLIVEIRA, R. R. Urbanising rainforests: emergent socioecologies in Rio de Janeiro, Brazil. Landscape History, v. 37, n. 2, p. 57-78, 2016.

CALAZANS, J. C. Iconografia de Khnum e iconografia de Harappā: exemplo de um mito de criação importado ou simples coincidência? Revista Lusófona de Ciência das Religiões, v. 4, n. 7, p. I73-I89, 2005.

CHAVES, C. M.; MARTINS, H. F.; CARAUTA, J. P. P.; LANNA-SOBRINHO, J. P.; VIANNA, M. C.; SILVA, S.A.F. Arboreto carioca 3. Rio de Janeiro: Centro de Conservação da Natureza, 1966. 28p.

CHITTIBABU, C. V.; PARTHASARATHY, N. Attenuated tree species diversity in humanimpacted tropical evergreen forest sites at Kolli hills, Eastern Ghats, India. Biodiversity and Conservation, v. 9, p. 1493-1519, 2000.

CORREAA, M. P. Dicionário das plantas úteis do Brasil e das exóticas cultivadas. Rio de Janeiro: Ministério da Agricultura, 1984. 764p. Vol. 4.

CRONON, W. The trouble with wilderness; or getting back to the wrong nature. Environmental History, n. I, p. 7-28, 1996.

CRUMLEY, C. Historical ecology: a multidimensional ecological orientation. In: CRUMLEY, C. (Ed.). Historical ecology: cultural knowledge and changing landscape. Santa Fe: School of American Research Press, I994.

CRUTZEN, P. J. Geology of mankind. Nature, v. 4I5, p. 23, 2002. 
DARWIN, C. The voyage of the beagle. New York: P. F. Collier \& Son, 1909.

DIEGUES, A. C. O mito moderno da natureza intocada. São Paulo: Hucitec, 1996.

DODARO, L.; REUTHER, D. Historical ecology: agency in human - environment interaction. In: KOPINA, H.; SHOREMAN-OUIMET, E. (Eds.). Routledge handbook of environmental anthropology. New York: Routledge, 2017.

ELTON, C. S. The ecology of invasions by animals and plants. Londres: Methuen, 1958.

ENGEMANN, C.; CHAGAS, J.; SANTOS, R. S.; BORGES, A. C.; OLIVEIRA, R. R. Consumo de recursos florestais e produção de açúcar no período colonial: o caso do Engenho do Camorim, RJ. In: OLIVEIRA, R. R. (Org.). As marcas do homem na floresta: história ambiental de um trecho urbano de Mata Atlântica. Rio de Janeiro: Editora PUC-Rio, 2005. p. II9-I42.

FERNANDEZ, A. C. F. Um rio de florestas: uma reflexão sobre o sentido da criação dos parques na cidade do Rio de Janeiro. Estudos Históricos, v. 24, n. 47, p. I4I-I6I, 2012.

FERRÃO, J. E. M. A aventura das plantas e os descobrimentos portugueses. 2. ed. Lisboa: Instituto de Investigação Científica Tropical, 1992.

FRAGA, J. S.; OLIVEIRA, R. R. Social metabolism, cultural landscape, and social invisibility in the forests of Rio de Janeiro. In: CANEVACCI, M. (Org.). Polyphonic anthropology - theoretical and empirical cross-cultural field-work. Rijeka: InTech, 2012. p. I39-I56.

GLASER, M.; RATTER, B.; KRAUSE, G.; WELP, M. New approaches to the analysis of human nature relations. In: GLASER, M.; KRAUSE, G.; RATTER, B. M. W.; WELP, M. (Eds.). Human nature interactions in the anthropocene: potentials for socio-ecological systems analysis. New York: Routledge, 2012.

GOMES, B. A. Observações botânico-médicas sobre algumas plantas do Brasil. Memórias da Real Academia das Sciencias de Lisboa. In: Gomes, B. A. (Org.). Plantas medicinais do Brasil, São Paulo: Edusp, 1972. p. I-IO4. (Brasiliensia Documenta, V). I8I2 t. III.

HALLET, L. M.; STANDISH, R. J.; HULVEY, K. B.; GARDENER, M. R.; SUDING, K. N.; STARZOMSKI, B. M. et al. Towards a conceptual framework for novel ecosystems. In: Hobbs, R. J.; Higgs, E. S.; Hall, C; M. (Eds.). Novel ecosystems: intervening in the new ecological world order. Oxford: Wiley-Blackwell, 20I3. p. I2-I8.

HAQ, N. Jackfruit, Artocarpus heterophyllus. Southampton: Centre for Underutilized Crops, University of Southampton, 2006.

HARRIS, J.; MURPHY, S.; NELSON, C.; PERRING, M.; TOGNETTI, P. Characterizing novel ecosystems: challenges for measurement. In: HOBBS, R.; HIGGS, E.; HALL, C. (Orgs.). Novel ecosystems: Intervening in the new ecological world order. Oxford: Wiley-Blackwell, 2013.

HOBBS, R. J.; ARICO, S.; ARONSON, J.; BARON, J. S.; BRIDGEWATER, P.; CRAMER, V. A. et al. Novel ecosystems: theoretical and management aspects of the new ecological world order. Global Ecology and Biogeography, v. I5, p. I-7, 2006. 
HOBBS, R. J.; HIGGS, E. S.; HALL, C. M. Defining novel ecosystems. In: Hobbs, R. J.; Higgs, E. S.; Hall, C. M. (Eds.). Novel ecosystems: intervening in the new ecological world order. Oxford: Wiley-Blackwell, 20I3. p. 58-62.

HUTTER, L. M. Navegação nos séculos XVII e XVIII. Rumo: Brasil. São Paulo: Edusp, 2005.

JARRET, F. M. Studies in Artocarpus and allied genera, III. A revision of Artocarpus subgenus artocarpus. Journal of the Arnold Arboretum, v. 4O, n. 4, p.I-IO, 1959.

MARRIS, E. Rambunctious garden. Saving nature in a post-wild world. New York: Bloomsbury. 2011 .

MCNEIL, J. R. The state of the field of environmental history. Annual Review of Environment and Resources, v. 35, p. 345-374, 2010.

MORAES SILVA, A. Diccionario da lingua portugueza composto pelo padre D. Rafael Bluteau, reformado e accrescentado por Antonio de Moraes Silva. Lisboa: Officina de Simão Thaddeu Ferreira, 1789. Vol. I.

MORTON, J. F. The jackfruit (Artocarpus heterophyllus Lam.) its culture, varieties and utilization. Proceedings of the Florida State Horticultural Society, v. 78, p. 336-344, 1965.

OLIVIERA, R. R. Mata atlântica, paleoterritórios e história ambiental. Ambiente e Sociedade, v. 4, n. 2, p. II-23, 2007.

OLIVEIRA, R. R. O machado e a floresta. Opiniões, v. 6, p. 25-25, 2012.

OLIVEIRA, R. R.; ENGEMANN, C. História da paisagem e paisagens sem história: a presença humana na floresta atlântica do sudeste brasileiro. Esboços, v. I8, p. 9-3I, 20 II.

OLIVEIRA, R. R.; FRAGA, J. S.; BERCK, D. E. Uma floresta de vestígios: metabolismo social e a atividade de carvoeiros nos séculos XIX e XX no Rio de Janeiro, RJ. INTERthesis, v. 8, p. 286315, 2011.

OLIVEIRA, R. R.; BERCK, D. E. ; BEZERRA, R. V. M. ; FRAGA, J. S. Driving forces in landscape transformation and space production in the mountains and lagoons of Rio de Janeiro, Brazil. Wuerzburger Geographische Arbeiten, v. 79, p. 9-17, 2012.

OLIVEIRA, R.; SOLÓRZANO, A. Três hipóteses ligadas à dimensão humana da biodiversidade da mata atlântica. FRONTEIRAS: Journal of Social, Technological and Environmental Science, v. 3, n. 2, p. 80-95, 2014 .

POORTER et al. Biomass resilience of neotropical secondary forests. Nature, n. 530, p. 2 II-2 I4, 2016.

RIO DE JANEIRO. Secretaria Municipal de Meio Ambiente. Inventário da cobertura arbórea da cidade do Rio de Janeiro. Rio de Janeiro: Prefeitura da Cidade do Rio de Janeiro, 2015. 232p. Vol. I.

SCUC. Jackfruit Artocarpus heterophyllus. Field manual for extension workers and farmers. Southampton: SCUC, UK, 2006. 
SILVA, T. T. A.; SOUZA, L. A.; OLIVEIRA, L. M.; GUIMARÃES, L. M. Temperatura de germinação, sensibilidade à dessecação e armazenamento de sementes de jaqueira. Revista Ciência Agronômica, v. 38, n. 4, p. 436-439, 2007.

SOLÓRZANO, A.; CABRAL, D. C.; OLIVEIRA, R. R. Introdução de espécies, produção de carvão e a história ambiental das florestas urbanas do Rio de Janeiro. In: FERREIRA, A.; RUA, J.; MATTOS, R. C. (Org.). Desafios da metropolização do espaço. Rio de Janeiro: Consequência, 2015. p. 85-IO4. Vol. I.

SOLÓRZANO, A.; OLIVEIRA, R. R.; LAZOS-RUIZ, A. E. Landscape reading methodology of urban forests: interpreting past and current socioecological interactions in Rio de Janeiro. Historia Ambiental Latinoamericana y Caribeña (HALAC), v. 6, p. 21 I-224, 2016.

SOLÓRZANO, A.; SALES, G. P. S.; PIZZOLANTE, H. N. Geografia, história e ecologia: bases fundamentais para investigar a transformação da paisagem do Vale do Rio Paraíba do Sul. In: OLIVEIRA, R. R.; RUIZ, A. E. Geografia histórica do café no vale do Rio Paraíba do Sul. Rio de Janeiro: Ed. PUC-Rio. p. 19-36, 2018.

SOLÓRZANO, A.; SALES, G. P. S.; NUNES, R. S. O legado humano na paisagem do Parque Nacional da Tijuca: uso, ocupação e introdução de espécies exóticas. FRONTEIRAS: Journal of Social, Technological and Environmental Science, v. 7, p. 15-36, 2018.

TANSLEY, A. G. The use and abuse of vegetational concepts and terms. Ecology, v. I6, n. 3, p. 284307, 1935 .

THOMAS, C. A. Jackfruit, Artocarpus heterophyllus Lam. (Moraceae), as source of food and income. Economic Botany, v. 34, p. I54-159, 1980.

UNESCO-SCBD (Joint program between biological and cultural diversity). Florence Declaration on the Links between Biological and Cultural Diversity, Florence (Italy), II abr. 2014.

VELLOSO, V. P. Farmácia na corte imperial (I85I-I887): práticas e saberes. 2007. Tese (Doutorado em História das Ciências da Saúde) - Programa de Pós-graduação em História das Ciências da Saúde, Fundação Oswaldo Cruz, Rio de Janeiro, 2007.

VILHENA, L. S. A Bahia no século XVIII. Salvador: Itapuã, 1969. Vol. 3.

WESTLEY, F.; CARPENTER, S.; BROCK, W.; HOLLING, C.; GUNDERSON, L. Why systems of people and nature are not just social and ecological systems. In: GUNDERSON, L.; HOLLING, C. (Eds.). Panarchy: understanding, transformations in human and natural systems. Washington, D.C.: Island Press, 2002.

YUNG, L.; SCHWARZE, S.; CARR, W.; Chapin III, F.; MARRIS, E. Engaging the public in novel ecosystems. Novel ecosystems. In: HOBBS, R.; HIGGS, E.; HALL, C. (Orgs.). Novel ecosystems: intervening in the new ecological world order. Oxford: Wiley-Blackwell, 2013. 